\title{
Correction to: Dietary L-glutamine supplementation modulates microbial community and activates innate immunity in the mouse intestine
}

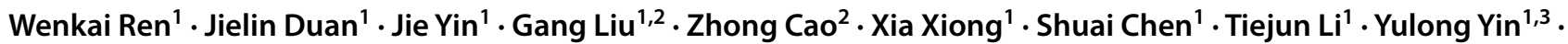 \\ Yongqing $\mathrm{Hou}^{3} \cdot$ Guoyao $\mathrm{Wu}^{3,4}$
}

Published online: 11 January 2021

(c) Springer-Verlag GmbH Austria, part of Springer Nature 2021

\section{Correction to: Amino Acids (2014) 46:2403-2413 https://doi.org/10.1007/s00726-014-1793-0}

In the published article, the images for Actin in Figs. 4a, 5a, $6 \mathrm{a}$, and $6 \mathrm{c}$ were incorrectly presented. This error does not affect the conclusion of the study. The corrected images for Actin are shown below.
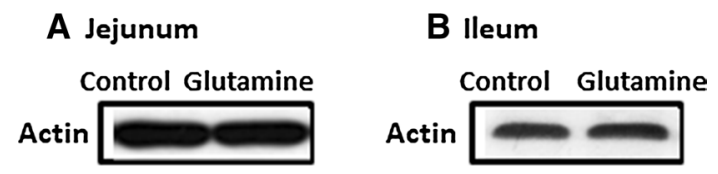

The original article can be found online at https://doi.org/10.1007/ s00726-014-1793-0.

Xia Xiong

$\mathrm{xx} @$ isa.ac.cn

Wenkai Ren

renwenkai19@126.com

1 Key Laboratory of Agro-ecological Processes in Subtropical Region, Scientific Observing and Experimental Station of Animal Nutrition and Feed Science in South-Central China, Ministry of Agriculture, Hunan Provincial Engineering Research Center of Healthy Livestock, Institute of Subtropical Agriculture, The Chinese Academy of Sciences, Changsha 410125, Hunan, China

2 Hunan Provincial Key Laboratory of Materials Protection for Electric Power and Transportation, School of Chemistry and Biological Engineering, Changsha University of Science and Technology, Changsha 410004, China

3 Hubei Key Laboratory of Animal Nutrition and Feed Science, Hubei Collaborative Innovation Center for Animal Nutrition and Feed Safety, Wuhan Polytechnic University, Wuhan 430023, China

4 Department of Animal Science, Texas A\&M University, College Station, TX 77843, USA
Figure legend: a The corrected images of Actin for Figs. 4a and $6 \mathrm{a} ; \mathbf{b}$ the corrected images of Actin for Figs. 5a and 6c.

Publisher's Note Springer Nature remains neutral with regard to jurisdictional claims in published maps and institutional affiliations. 